\title{
Rational selection of legal specialty texts for students studying law in the aspect of professionally-oriented reading
}

\author{
Yulia Voropaeva ${ }^{1 *}$, Zulfira Zyukina ${ }^{1}$, Pavel Sapozhnikov ${ }^{1}$, Svetlana Razuvanova ${ }^{2}$, \\ Tatyana Yakovleva, ${ }^{1}$ and Andrey Sychev ${ }^{3}$ \\ ${ }^{1}$ RUDN University, 6 Miklukho- Maklaya St, Moscow, 117198, Russian Federation; \\ ${ }^{2}$ State budgetary educational institution of the city of Moscow "School No. 2120", Atlasova street, 7, \\ building 3, Moscow 108811, Russian Federation \\ ${ }^{3}$ Ogarev Mordovia state University, 68 Bolshevitskaya St, Saransk, Russian Federation
}

\begin{abstract}
The article deals with topical issues of the practice of teaching specialty language to law students. The authors of the article work with students of different specialties and teach such disciplines as: Russian as a foreign language, Russian in professional activities of international lawyers, the basics of rhetoric and communication, Russian in the field of jurisprudence, Russian and the culture of speech, the oratory of a lawyer.
\end{abstract}

\section{Introduction}

To raise the efficiency of professionally-oriented reading, legal texts should be selected rationally, thus constituting the linguistic component of teaching Russian as a foreign language. By such rational selection of authentic legal texts, in texts chosen for training we single out the qualitative and quantitative features, most relevant for the purposes of teaching professionally-oriented reading. Based on our choice of texts, we clarify the principles of selection and formulate conditions that ensure compliance with these principles. In the methodology of teaching Russian as a foreign language there is a whole section devoted to qualitative features of texts from the point of view of their relevance for the purposes of teaching.

\section{Methodology}

Specialists in methodology consider that the information content of texts should be regarded as one of the features a training text for reading should possess. There is no unified definition of the term "the information content of a text", though in methodology information content is viewed as an obligatory marker of a training text used in teaching. Such disciplines as linguistics, psychology, communication theory, and psycholinguistics also define texts for training purposes as a component of teaching foreign-language speech production. What are the requirements for choosing a training text? First of all, it is the presence of definite grammar phenomena corresponding to the level of the students' language preparation (in the testing on Russian as a foreign language TRKI the certified

*Corresponding author: voropaeva_yua@pfur.ru 
levels are A1, A2, B1. B2, C1, C2). Also the presence of the necessary and sufficient basic vocabulary stock is important, as well as the cohesion and coherence of the text, the unity of its meaning and how its composition is structured. In compliance with the purposes of teaching professionally-oriented reading we should look at an authentic text as a product of speech that emerged in the system of a particular language and was created with a particular communicative purpose. According to the above, for the methodology of teaching not only standard text formation is important, but also the aspects that allow to distinguish texts from one another: whether a text is easy/difficult for understanding, whether it is interesting or not, whether it is sought-after or not, etc.[1].

\subsection{Objects and Methods}

While selecting methods and approaches for scientific search of basic principles to classify texts in specialty language, we looked at spheres of communication. Each text possesses its particular typical and specific features. Namely this typicality is a relevant criterion for the selection of materials in the field of law, as they represent linguistic, compositional and structural features of legal documents in the best way.

It is exactly the legal language that is distinguished through a complex terminology, so the aim is to lay an elaborate terminological basis of the specialty language, to form pragmatic competence and to raise the level of professional competence of students who study law. For these purposes we see the criterion of the terminological value as the most sought-after criterion in choosing training texts.

Defining the main spheres of communication included in the curriculum of professionallyoriented teaching of Russian as a foreign language, we proceed from the real practical usage of the language as a means of communication, trying to satisfy the cognitivecommunicative interests and to meet the professional needs of learners. For example, such spheres of written and oral discourse are relevant as documents regulating the court procedures and the functioning of the judicial system; documents presented at trials, types of courts; recourse to court and its legal forms; applications to court; complaints connected or not connected with proceedings; documents for the registry of court and public reception offices; documents regulating the conduct, rights and duties of those taking part in legal proceedings; legal documents; documents regulating general rules of enforcement proceedings and conduct while enforcing court decisions, etc. Pragmatic materials have their place in each of these spheres. [2]. We have analyzed more than 450 texts of authentic legal documents that could be used in the process of teaching the specialty language in the $1^{\text {st }}-4^{\text {th }}$ year of bachelor studies.

Thus, in the third year of bachelor studies we work with authentic professional texts, namely:

FORMS OF PROCEDURAL DOCUMENTS FOR INVESTIGATION OFFICERS (ORDERS): Order on initiating a claim to court for leave to inspect a place of residence. Order on initiating a claim to the head of the investigation office for leave to prolong the term of checking the report of a crime.

As a part of specific vocabulary training, we look at legal, civil and arbitration proceedings; procedural documents on civil cases; templates of criminal cases. [6].

Such extensive factual material allowed to systematize the text corpus of legal documents used in the process of reading training. The required texts should represent the main spheres of communication, correspond to the contents of the course that future lawyers are taking, and cover the main communicative situations, meeting the cognitivecommunicative needs and taking into account the specific features of legal documents at the same time. 


\section{Results}

Not only the topic and the sphere of communication, but also the reader's cognitivecommunicative needs can serve as a basis for classification of various situations, in which it is presupposed to use authentic texts of legal documents as sources of information. As we see it, namely the need for professional communication motivates readers to work with legal texts and set the tactic and the strategy of reading, for example, such as summarizing information from legal texts, or search and orientating information for the future use in their work. The productivity of professionally-oriented reading of legal texts is linked to its targeted and efficient organization. To ensure the selection of means most suitable for these purposes we should take into account the particular structural features of this type of discourse. Optimal balance between speech production and a certain level of activity gives an opportunity to regulate the formation of this activity more accurately. Reading legal texts facilitates the development of cognitive interest, as legal texts represent a source of cognition that stimulates intellectual activity of the reader. Authenticity of a legal document, its definitely structured form, unambiguity of statements, rigid and precise terminology affect emotions and will.

In the legal substyles the following written genres are singled out - legal act, decree, constitution, order, law.

The jurisdictional substyle exists both in written and in oral forms. In the written discourse there are such genres as: sentence, legal act, the form of the investigator officer's protocol, indictment, amnesty decree...

In the spoken discourse we have: interview, interrogation, speech in court, communication during the reception of citizens, the defending lawyer's speech...

Legal documents must be coordinated, coherent and corresponding to the legislative practices accepted in the state. The main thing for legal and jurisdictional documents is to have exact, clear, full wordings that leave no place for ambiguity (no double meaning). "Excessive simplification of legal language can lead to its vulgarization; can hinder correct expressing of some subtlety of legal regulations" [4].

The exactness of statements is more important than the transparency of the text. "Nothing must be left implicit. The thought suggested by a law-maker that has found no expression in the text of the law, does not make a law: what cannot be expressed, cannot be clarified" [5].

Variations and connotations are a negatively coloured phenomenon in comprehension of legal texts. They contradict the purpose of the law as a form of organizing a society's life.

"The requirement of unambiguous comprehension of meaning defines the linguistic features of all legal documents" [5].

\section{Conclusion}

Consequently, we can make a conclusion that proceeding from the purpose of teaching Russian as a foreign language and focusing on the final result of training reading skills, we need to take into account not only special communicative skills and competences, which characterize the practical level of Russian as a foreign language, but we should also include the topics of communication, communicative situations and the given communicative intentions into teaching of this type of activity. In this case we will be able to present the selected language material - authentic legal documents and texts - in a structured form. Systematization of legal texts is based on the following principles: quantitative sufficiency and genre representativeness, cohesion of the subject and unity of the topic. We suppose 
that such text corpus will provide a solid foundation for training professionally-oriented reading as a stage of developing foreign-language communicative competence.

\section{Acknowledgements}

This work was supported by the Russian Foundation for Basic Research, grant No. 19-01100082

This paper was financially supported by the Russian Foundation for Basic Research, grant No. 20-012-22046

\section{References}

1. Yu.A. Voropaeva, Methods of teaching professionally-oriented reading based on advertising and PR texts, Moscow (2008)

2. O.N. Diordieva, How to behave in court. What students are not taught: an educational guide, Moscow (2019)

3. S.A. Khavronina, I.V. Gulyayeva, Psycholinguistics and methods of teaching Russian as a foreign language. Russian Language Studies, Moscow (2013)

4. B.P. Spasov, The law and its interpretation, Moscow (1986)

5. T.V. Gubaeva, Judicial act as a special text. Legal LINGUISTICS. Publisher: Altai state University, Barnaul (2011)

6. N.A. Kolokolov, A.N. Razinkina, R.V. Yartsev, Samples of procedural documents, Judicial proceedings, Moscow, (2016)

7. O. A. Bakhareva, T. M. Tsepkova, S. A. Filippov, Collection of procedural documents in civil cases: educational and methodological guide/comp.,Saratov, (2015) 